\title{
Energy Efficiency and Productivity of China: Compared with Other Countries
}

\author{
X.P. Xu and L. Liang \\ School of Management, University of Science and Technology of China \\ He Fei, An Hui 230026, P.R. China \\ cicilj@mail.ustc.edu.cn, lliang@ustc.edu.cn
}

\begin{abstract}
Energy intensity(EI) is a commonly used index to estimate energy efficiency(EE) for countries, but it neglects the specific structure of energy consumption. We present a new index named weighted energy intensity(WEI), where weights are computed by a linear programming model named weighted energy intensity model(WEIM) and prove that it is equal to CCR model in DEA with one-output system. A comparison between WEI and EI is demonstrated. Results show that EI has underestimated EE of China and WEI is more accordant with real situation. We also use malmquist index(MI) to analyze changes of EE, frontier technology and total factor productivity of China over period 2000-2003.
\end{abstract}

Keywords: Weighted energy intensity, Energy productivity, Energy efficiency, DEA; Malmquist index.

\section{Introduction}

China has become the second greatest energy consumption country in the world. According to BP Statistical Review of World Energy, Chinese primary energy consumption increased by $15.1 \%$ in 2004. That's much higher than world primary energy consumption's 4.4\% [1]. Energy intensity(EI) is a popular index to estimate energy efficiency(EE) for a country, which is defined as total energy consumption relative to total output(GDP or GNP) 2. Using energy intensity, most researches support that EE of China is low. However, EI only considers simple-sum of energy consumption as single input to produce GDP neglecting structure of energy consumption. Usually, EI may overstate or understate energy efficiency. We present a new index named weighted energy intensity(WEI), where weights are computed by weighted energy intensity model(WEIM). We prove that WEIM is equal to CCR model in data envelopment analysis(DEA) and can easily overcome that shortage of EI. The same as CCR model, WEIM is a non-parametric approach that computes best practice efficient frontiers based on convex combinations of decision making units(DMUs) in the sample 3]. WEIM requires few assumptions and get results more objectively than EI.

Section 2 shows sample selection, inputs and output. Section 3 introduces WEI, WEIM, CCR and malmquist index(MI). WEIM is used to estimated EE of China among 49 countries and MI is used to analyze total factor productivity changes over the period 2000-2003 in section 4. Finally, we conclude. 


\section{Sample Selection, Inputs and Output}

Two data sources are used, which are World Petroleum Yearbook 4 and International Statistical Yearbook [5. Removing countries that didn't satisfy our sample selection criteria, we got 49 countries. They are United States, China, Russia Federation, Japan, India, and so on.

Most researches about the relationship between energy consumption and economic growth focus on how the latter impacts the former. However, experience has proved that it's very important for energy to drive economic growth 6 . We concentrate on production process where energy consumption is input and GDP is output. Main primary energy consumption concludes oil, natural gas, coal, nuclear energy and hydropower. Oil and natural gas consumption are incorporated as one input. Nuclear power and hydropower are also incorporated as another input. Coal is the third input. Gross Domestic Product (GDP) is the only output. Therefore, we have three input indexes(million tones oil equivalents) and one output index(100 million USD).

\section{Methodology}

Suppose that there are $n$ countries to be evaluated. Each country consumes various amounts of $m$ different energy inputs to produce GDP. Specifically, country $j$ consumes amount $x_{i j}$ of energy input $i$ to produce amount $y_{j}$ of GDP. We assume that $x_{i j} \geqslant 0$ and $y_{j} \geqslant 0$. WEI is defined as weighted energy consumption relative to total GDP. Weights are not selected subjectively, but through solving a linear programming model named WEIM, specific form of which is as follows.

$$
\min \rho=\sum_{i=1}^{m} p_{i} x_{i 0} / y_{0} \quad \text { subject to } \sum_{i=1}^{m} p_{i} x_{i j} / y_{j} \geq 1(\forall j), \quad p_{i} \geq 0(\forall i) .
$$

The target value of this model is WEI of country $0 . p_{i}$ represents weight of input $i$. WEIM adopts a self-evaluation mechanism. Each country can get different combinations of $p$ to maximize its WEI score.

Definition 1. Country 0 is WEI efficient if there exists an optimal solution that $\rho^{*}=1$ and $p_{i}^{*}>0(\forall i)$.

DEA is a relatively data oriented approach for evaluating performance of DMUs which convert multiple inputs into multiple outputs [3]. The following CCR model[7], one of DEA models, is corresponding model for our research.

$$
\max \theta=u y_{0} / \sum_{i=1}^{m} v_{i} x_{i 0} \text { subject to } u y_{j} / \sum_{i=1}^{m} v_{i} x_{i j} \leq 1(\forall j), u \geq 0, v_{i} \geq 0(\forall i) \text {. }
$$

Definition 2. Country 0 is DEA efficient if there exists an optimal solution that $\theta^{*}=1$ and $u^{*}>0, v_{i}^{*}>0(\forall i)$.

Theorem 1. WEIM is equal to CCR model, and $\rho^{*}=1 / \theta^{*}, p_{i}^{*}=v_{i}^{*} / u^{*}(\forall i)$. Proof. Take reciprocal of $\theta$ and let $p_{i}=v_{i} / u(\forall i)$ in CCR model, then CCR model can be easily turned into WEIM. 
MI is an index representing total factor productivity growth of a DMU under multiple inputs and multiple outputs framework. MI is defined as the product of "Catch-up" (CU) and "Frontier-shift" (FS) terms. CU relates to the degree that a DMU attains for improving its efficiency, while FS reflects the change in the efficient frontiers surrounding the DMU between the two time periods. $M I>1$ indicates progress in total factor productivity, while $M I=1$ and $M I<1$ indicate respectively the status quo and decay in total factor productivity. $\mathrm{CU}$ and FS have similar explanations with MI[3].

\section{Results}

This paper primarily focuses on China and compares China with other countries. We use WEIM to compute energy efficiency for 49 countries and compare WEI with EI. To get a clear image of China, we just involve top five energy consumption countries among 49. Results are showed in Table 1. Using EI index, China is one of the lowest EE countries, of which rank is 43 and EI is 831.47 toe/10000 USD. EI of Russia Federation is lower than China, but EI of other three, including India, are higher than China. Main energy resource of China is coal, which makes up of nearly $70 \%$ of its energy consumption. Most other countries consume oil and natural gas. Usually, combustion efficiency of coal is lower than other kinds of energy. EI neglects this specific characteristic of different energy, but WEI can easily overcome this shortage. In WEIM, each country get different combinations of $p$ to maximize its WEI score. Using WEI, rank of China is upgraded from 43 to 32 . EE of Russia Federation is lower than China, while EE of United States and Japan are higher than China. Japan and United States are developed countries, after two oil crisis, they have made great efforts to improve their EE. India is a fast developing country like China and its WEI score is a little lower than China, which gives different result from EI. EI index has underestimated EE of China and WEI is more accordant with real situation.

Now let's examine the energy productivity changes of China over period 20002003. Results are showed in Table 2. From year 2000 to year 2001, MI of China is equal to 1.08 , which implies slight progress in total factor productivity. The reason is high catch-up term of 1.20 , which means great improvement in efficiency. Frontier-shift term is lower than 1, so the efficiency frontier has withdrew back. Not only for China, but also other four countries are confronted with regress

Table 1. Efficiency Scores and Rank by EI and WEI in 2003

\begin{tabular}{lccccc}
\hline Country & \multicolumn{2}{c}{ EI } & & \multicolumn{2}{c}{ WEI } \\
\cline { 2 - 3 } \cline { 5 - 6 } & EI & rank & & $\rho$ & rank \\
\hline United States & 209.87 & 16 & & 1.90 & 21 \\
China & 831.47 & 43 & & 3.19 & 32 \\
Russia Federation & 1549.55 & 46 & & 15.70 & 47 \\
Japan & 117.37 & 3 & & 1.09 & 5 \\
India & 575.09 & 38 & & 3.24 & 33 \\
\hline
\end{tabular}


Table 2. Catch-up, Frontier-shift and Malmquist Index Over Period 2000-2003

\begin{tabular}{lccccccccc}
\hline Country & \multicolumn{3}{c}{$2000-2001$} & \multicolumn{3}{c}{$2001-2002$} & \multicolumn{3}{c}{$\underline{2002-2003}$} \\
& CU & FS & MI & CU & FS & MI & CU & FS & MI \\
\hline United States & 1.12 & 0.93 & 1.05 & 0.96 & 1.05 & 1.01 & 0.85 & 1.24 & 1.06 \\
China & 1.20 & 0.90 & 1.08 & 1.01 & 1.01 & 1.02 & 0.81 & 1.22 & 0.99 \\
Russia Federation & 1.25 & 0.94 & 1.17 & 1.05 & 1.07 & 1.12 & 0.97 & 1.25 & 1.21 \\
Japan & 1 & 0.88 & 0.88 & 1 & 0.97 & 0.97 & 0.92 & 1.21 & 1.11 \\
India & 1.13 & 0.93 & 1.05 & 1.00 & 1.04 & 1.05 & 0.85 & 1.25 & 1.06 \\
\hline
\end{tabular}

in the frontier technology. From year 2001 to year 2002, both catch-up and frontier-shift term of China are higher than 1, which means efficiency frontier moves upward and efficiency of China is improved, thus the MI is higher than 1. From year 2002 to year 2003, MI of China is lower than 1, showing slight regress in total factor productivity. Frontier-shift term is equal to 1.22 , while catch-up term of China is equal to 0.81 and that is lower than other four countries.

\section{Conclusion}

This study has presented a index named WEI which overcomes one shortage of traditional energy intensity index and proved WEIM is equal to CCR model with one output in DEA. Energy efficiency in 2003 and productivity of China over period 2000-2003 were analyzed using WEIM and MI methods with a three-inputs and one-output system. Results showed that WEI were more accordant with the real situation than EI and EI underestimated energy efficiency of China. Using WEI, rank of China has been upgraded greatly. Evidences were also provided that total factor productivity of China increased over 2000-2002, decreased a little over 2002-2003, and increase rate over 2000-2002 was slow down.

Researches can be continued to do with this topic. This paper only considered total GDP as single output. Structure of GDP can be involved. Having evaluated the energy efficiency before, we can go on to forecast future efficiency trend.

Acknowledgments. This work was supported by NSFC (No.70525001).

\section{References}

[1] British Petroleum: 2005 Statistical Review of World Energy. http://www. bp.com.

[2] Ang, B.W.: Decomposition of industrial energy consumption: the energy intensity approach[J]. Energy Economics 16(1994), 163-174

[3] Willian W. Cooper, Lawrence M. Seiford and Joe Zhu: Handbook on Data Envelopment Analysis [M]. Kluwer Academic Publishers. (2004) 8-12, 203-207

[4] CPETRC: World Petroleum Yearbook[M]. Petroleum Industry Press.(2005)203-204

[5] NBSC: International Statistical Yearbook[M]. China Statistical Press. (2005)46-50

[6] International Energy Agency: World Energy Outlook[M]. Paris: OECD. (2004).

[7] Charnes, A., Cooper, W.W., Rhodes, E.: Measuring the efficiency of decision making units. European Journal of Operational Research 2 [J]. (1978)429-444 